\title{
Low intensity surface fire instigates movement by adults of Calosoma frigidum (Coleoptera, Carabidae)
}

\author{
Jenna M. Jacobs ${ }^{1, \dagger}$, J. A. Colin Bergeron ${ }^{2, \ddagger}$, Timothy T. Work ${ }^{1, \S}$, John R. Spence ${ }^{2, \S}$ \\ I Département des Sciences Biologiques, Université du Québec à Montréal, Pavillon des sciences biologiques \\ (SB), 141 Avenue du Président-Kennedy Montréal (Québec), H2X 1 Y4, Canada 2 Department of Renewable \\ Resources, University of Alberta, 751 General Services Building, Edmonton, Alberta, T6G 2H1, Canada
}

Corresponding author: Jenna M. Jacobs (email@jennajacobs.org)

Academic editor: T. Erwin | Received 14 September 2011 | Accepted 20 September 2011 | Published 16 November 2011

Citation: Jacobs JM, Bergeron JAC, Work TT, Spence JR (2011) Low intensity surface fire instigates movement by adults of Calosoma frigidum (Coleoptera, Carabidae). In: Erwin T (Ed) Proceedings of a symposium honoring the careers of Ross and Joyce Bell and their contributions to scientific work. Burlington, Vermont, 12-15 June 2010. ZooKeys 147: 641-649. doi: 10.3897/zookeys.147.2084

\begin{abstract}
The genus Calosoma (Coleoptera: Carabidae) is a group of large, sometimes ornate beetles, which often voraciously attack caterpillars. Many studies have reported Calosoma beetles being highly conspicuous during defoliator outbreaks. Based on observations of individual beetle behavior, patterns of activity density and phenology we provide a hypothesis on how environmental cues may synchronize Calosoma activity with periods of high defoliation. We have observed that adults of Calosoma frigidum construct underground burrows similar to those reported to be created by larvae for pupation. We propose that small increases in soil surface temperature caused either by defoliation events or decreased albedo of blackened, burned soil causes beetles to leave their underground burrows and begin foraging. Indirect support for this hypothesis comes from high levels of adult $C$. frigidum collected in relatively small patches of burned forest $\left(<200 \mathrm{~m}^{2}\right)$ relative to the surrounding mosaic of unburned forest shortly after a prescribed surface burn.
\end{abstract}

\section{Keywords}

Calosoma, foraging, behavior, prescribed fire, defoliation

\section{Introduction}

Calosoma frigidum Kirby, also known as "The Cold Country Caterpillar Hunter" (Erwin 2007) has long been of interest to entomologists because of its voracious appe-

Copyright Jenna M. Jacobs et al.. This is an open access article distributed under the terms of the Creative Commons Attribution License, which permits unrestricted use, distribution, and reproduction in any medium, provided the original author and source are credited. 
tite for caterpillars (Burgess and Collins 1917). Adults are macropterous, good flyers and frequently climb trees to feed on caterpillars (Lindroth 1961). Larvae are known live on the ground and feed voraciously on lepidopteran pupae and larvae that have dropped to the ground (Larochelle and Larivière 2003; Lindroth 1961). Adults and larvae $C$. frigidum feed on a variety of defoliator species including satin moth (Wagner and Leonard 1980), bruce spanworm (Crins 1980), gypsy moth (Cameron and Reeves 1990), spruce budworm (Sanders and Frankenhuyzen 1979) and forest tent caterpillar (Parry et al. 1997), and can become highly conspicuous during outbreak periods (Cameron and Reeves 1990; Jacobs et al. 2008; Loesh 1977).

Prey density has been linked to Calosoma ovarian development, oviposition behaviour, and female activity (Jeffords and Case 1987; Spieles and Horn 1998; Weseloh 1993). Weseloh (1985) observed that populations of the introduced biological control agent, C. sycophanta, were high in years following collapse of lepidopteran outbreaks, however individuals were not active nor dispersing. Weseloh (1993) further found that few females would reproduce unless fed caterpillars in the first week after ending diapause, and furthermore, it is known that some adults remain dormant in overwintering soil cells all summer when moth numbers are low (Vasik 1972). This behavior may allow beetles to remain in an extended dormancy over multiple years when prey populations are low. Despite the obvious link between populations of Calosoma beetles and their prey, it remains unclear what signals trigger or inhibit activity of these caterpillar hunters.

Several studies have noted increased abundance of Calosoma beetles in pitfall traps in response to changes in habitat variables. Jacobs et al. (2008), for example, observed increased catch rates of $C$. frigidum after low levels of forest harvest, however catch rates declined when forest harvest exceeded 50\% intensity. Koivula et al. (2006) found a decline in catch rates with increased salvage harvesting. Other authors have shown that activity-density of $C$. frigidum along with that of a closely related species, Calosoma calidum (Fabricius), was positively impacted by burning, salvage harvesting and a herbicide treatment applied after harvesting, however catches of both these species in control stands were extremely low (Cobb et al. 2007).

Based on comparisons of pitfall trap catch rates $C$. frigidum in a mosaic of burned and unburned forest, we hypothesize that activity of $C$. frigidum is triggered by increased soil temperature. We explain that adult Calosoma construct an underground burrow, similar to that made for pupation (Larochelle and Larivière 2003) and documented for other Calosoma species (Vasik 1972), and suggest that they emerge from the burrow in response to soil warming caused by severe defoliation events. Alternatively, as we show here, activity may be increased when temperature is raised by the albedo of burned, blackened soil.

\section{Methods Study Site}

This study took place at the Ecosystem Management by Emulating Natural Disturbance (EMEND) research site in northwestern Alberta, Canada $\left(56^{\circ} 46^{\prime} 13^{\prime \prime} \mathrm{N}, 118^{\circ}\right.$ 
22 '28"W). The 10 ha stand chosen for the study was dominated by trembling aspen (Populus tremuloides Michx.) and balsam poplar (Populus balsamifera L.) with the understory dominated by green alder (Alnus crispa (Aiton)) and river alder (Alnus tenufolia Nuttall). Further information on the EMEND site and ground beetles responses can be found in Work et al. $(2010 ; 2004)$ and Jacobs et al. (2008).

On April 26 $6^{\text {th }}, 2000$ a low intensity prescribed burn using drip torches was initiated as an EMEND treatment. The severity of the fire was not sufficient to kill trees and by the end of May evidence of fire was limited to some superficial charcoal deposits on the forest floor and at the base of trees. Surveys of the stand following fire revealed a mosaic of patches where fire had consumed a small portion of the forest floor and scorched tree bases adjacent to patches with no evidence of fire.

Within the stand subjected to prescribed burning we selected four areas (each ca. $\left.100 \mathrm{~m}^{2}\right)$ in which burning was clearly evident and four additional areas with no evidence of burning, and installed two pitfall traps per area (16 in total) on June $5^{\text {th }}$, 2000. Our pitfall traps consisted of an outer permanent (1L) cup, acting as a sleeve to maintain the pit and minimize disturbance at checks, and a removable $(500 \mathrm{ml})$ inner cup (Spence and Niemelä 1994). Traps were filled with $200 \mathrm{ml}$ of silicate-free ethylene glycol as a killing agent and preservative and were covered with an elevated $10 \mathrm{~cm} \times 10 \mathrm{~cm}$ wood roof. Arthropods captured in the traps were collected every 2-3 weeks until August $16^{\text {th }} 2000$, and the sites were similarly resampled May $9^{\text {th }}$ to August $20^{\text {th }} 2001$. Samples were stored in $75 \%$ ethanol and all beetles in the samples were identified to the level of species.

In an effort to make general observations of the beetle, we examined five adult $C$. frigidum in the lab in $5 \mathrm{~L}$ glass jars, filled with about $10 \mathrm{~cm}$ of soil. These jars were left at room temperature for approximately 2 years.

\section{Data Analysis}

Community level analysis revealed virtually no effect of burning on the larger beetle community or on activity of any individual species except for $C$. frigidum. We therefore restricted the scope of this study to explaining the response of this species to the EMEND burning treatment. All analyses were conducted in R 2.12.1 (R Development Core Team 2010). Differences in C. frigidum catch rates between treatments and across collection dates was analyzed using a two factor repeated measures analysis of variance (RM-ANOVA) using the aov function. Tukey HSD post-hoc tests were carried out using the HSD.test function in the agricolae library of R (Felipe de Mendiburu 2009).

\section{Results}

We collected 298 individuals of $C$. frigidum, representing $14 \%$ of the total catch of 74 species. Catch rates of $C$. frigidum were significantly higher in the burned patches 
during the year of the fire (2000) than in the unburned patches or anywhere in the stand the following year (Figure 1, RM-ANOVA, Treat $x$ Year, $F_{1,6}=0.08, P=0.017$ ). The highest catch rates were recorded in the July $11^{\text {th }}$ collection in 2000 and for the June 21 in 2001 (Figure 2). However, despite similarity in activity pattern, the overall activity in 2000 was much higher than in the following year.

In the laboratory one of the adult beetles created a burrow ca. $4 \mathrm{~cm}$ under the soil surface as the soil dried. Whether the other beetles brought into the lab also subsequently created these burrows is unknown, as this behavior was not specifically under study.

\section{Discussion}

Increased catch rates of $C$. frigidum observed in the same year as the prescribed burn could be explained by either increased activity in burned plots or actual differences in population density between burned and unburned areas. While we are not capable of completely discounting this second explanation, we favor the first for several reasons. First, our study site was very homogeneous and the chances of all four burned patches being located in areas of high $C$. frigidum density and all four unburned patches in areas of low $C$. frigidum density seems low. Second, we observed increases in catch rates within the same year as the fire, discounting the possibility of increases due to reproduction. Thirdly, we feel it is unlikely that local densities increased as a result of immigration of $C$. frigidum into the burned areas for the following reasons. If local density increased, the 3-5 year life span (Larochelle and Larivière 2003) of this species would suggest that we should observe continued elevated activity-density in the years following the fire. Furthermore, if immigrants were attracted to the burn, we would also expect to see higher activity-density patterns in surrounding unburned areas during this period. Also, in a concurrent study on wood-associated beetles using flight traps, we collected just 9 individuals of $C$. frigidum with no patterns among treatments or between years. Together these three points suggest that the observed increases in catch rates are a function of increased activity rather than highly localized differences in density due to either reproduction or immigration.

We propose that the fire event itself had little direct influence on the beetles because it would have been of very short duration. Instead we posit that charcoal deposited on the soil surface in the wake of the fire resulted in higher soil temperature from decreased surface albedo. Sustained increases in soil temperatures from sun exposure in burned sites may be similar to those during severe defoliation and could serve as a signal to adult beetles to begin foraging when potential prey populations are high. This could explain the results of Cobb et al. (2007) who found high activity levels of both C. frigidum and C. calidum following an herbicide treatment on a young regenerating conifer stand. Under our hypothesis, removal of the dense shrub layer resulted in small increases in soil temperature prompting movement by these caterpillar predators.

Decreasing forest cover caused by forest harvest could also be associated with small increases in temperature of the soil surface, explaining why catch rates of $C$. frigidum 


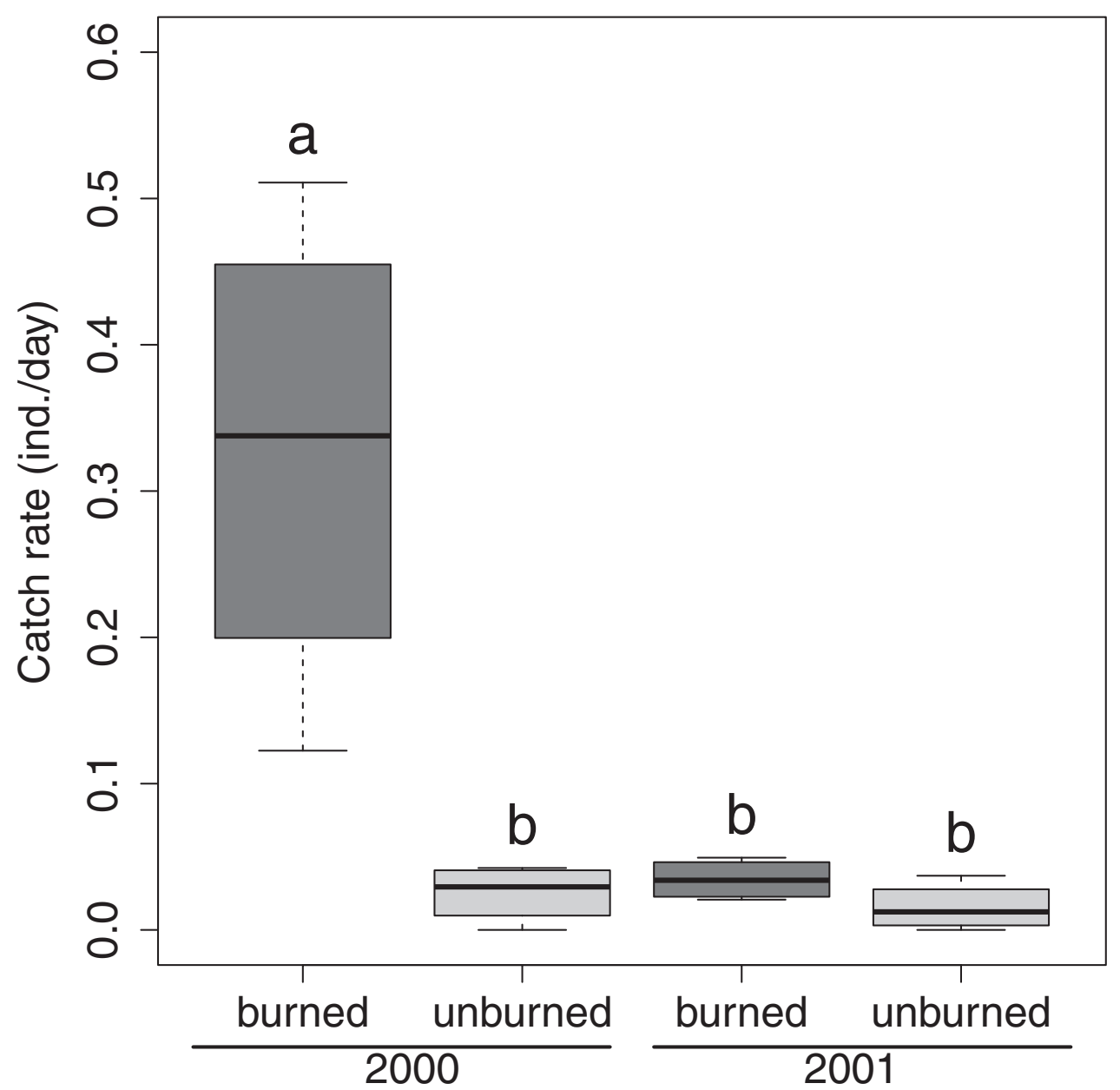

Figure I. Box and whisker plot of catch rates of Calosoma frigidum in burned and unburned patches. Letters denote the results of a Tukey's HSD post-hoc test following a 2 factor repeated measures ANOVA. Box represents the upper and lower quartiles divided by the median and whiskers are the largest and smallest values.

increased in residual strips compared to nearby dense forests in Maine (Jennings et al. 1986). This would also explain why the highest levels of capture were recorded at $50 \%$ green tree retention the 2 years following harvest at EMEND (Jacobs et al. 2008). Although it appears that small increases in the temperature of the soil surface could increase the activity of $C$. frigidum, results from EMEND suggest that the explanation cannot be simple. Clearly, the complete lack of trees after more intensive harvest was associated with cessation of activity by this beetle or perhaps with dispersal by flight. Retention levels below $50 \%$, quickly caused catch rates of $C$. frigidum to drop (Jacobs et al. (2008). Similarly, Koivula and Spence (2006) initially recorded high catch rates of $C$. frigidum following fire, and noted decreased catch rates as the intensity of salvage harvesting increased. 


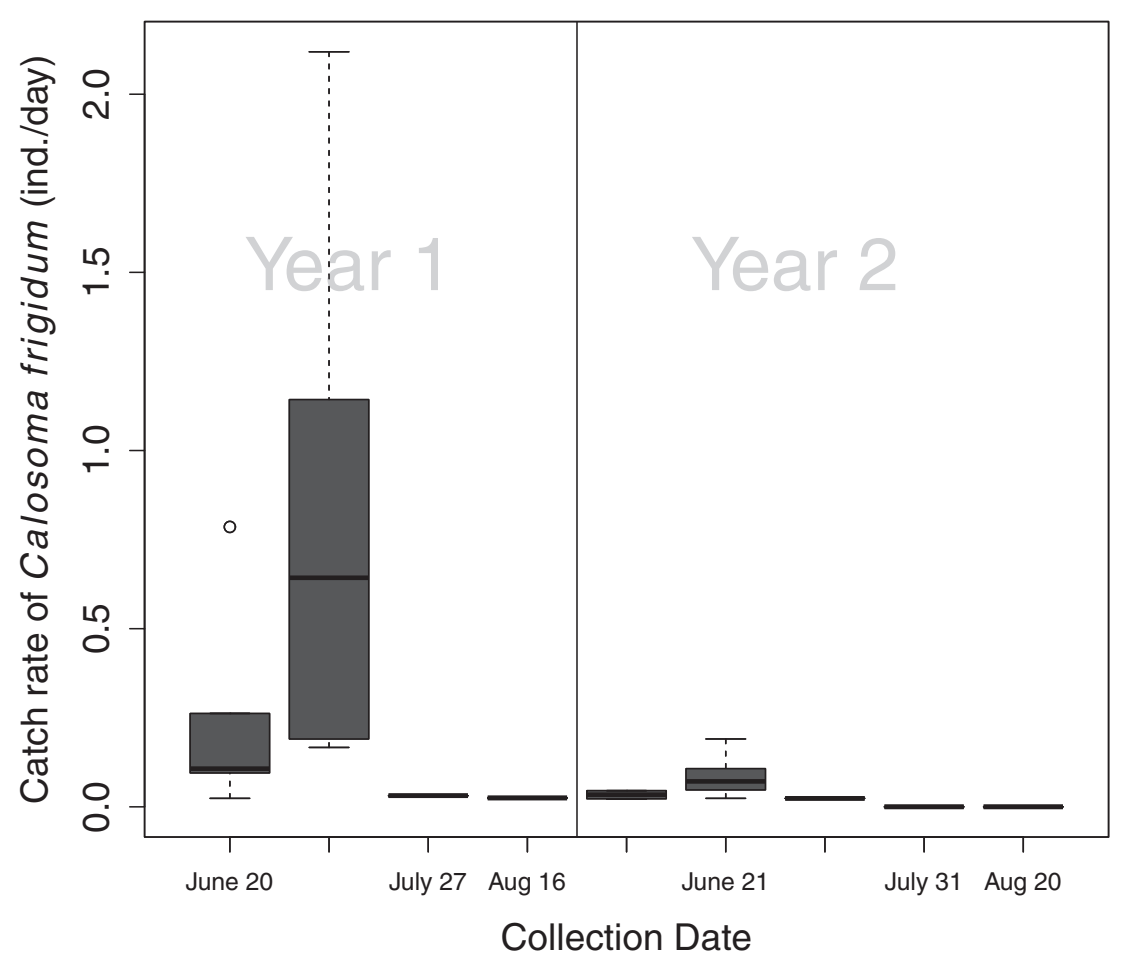

Figure 2. Box and whisker plot of catch rates in burned patches, by collection date, for the year of the fire (year 1) and the following year (year 2). Box represents the upper and lower quartiles divided by the median and whiskers are the largest and smallest values, excluding outliers represented by circles 0 .

The capacity of adult beetles to construct underground burrows in conjunction with their long life span may permit Calosoma to effectively exploit cyclic defoliator populations characteristic of the boreal zone (e.g., those of forest tent caterpillar, bruce spanworm and spruce budworm). Calosoma populations could initially build-up during an outbreak through a combination of both localized immigration from neighboring stands and emergence of resident adults from underground burrows within the stand. If defoliator populations remain high, both immigrants and residents could conceivably accumulate in the stand in adult burrows in the soil. When an outbreak collapses and there are no signals to emerge and run, these adults could lay dormant for several years. As the next outbreak unfolds, increased soil temperatures would effectively synchronize adult beetles with an increasing source of prey as well with potential viable congeners to facilitate reproduction. The proportions of these individuals that emigrate following the collapse or remain in adult burrows as a 'sit and wait' strategy should vary with outbreak frequency, but such data remain to be collected. 


\section{Conclusions}

We have offered a possible mechanism for initiating the foraging response in dormant Calosoma beetles, using specific evidence from $C$. frigidum in NW Alberta, Canada. Increases in the catch rate and activity patterns of Calosoma beetles have been recorded during defoliation events, herbicide treatments, mechanical canopy thinning and soil charcoal deposits following fire. All these events have the potential to warm the soil surface in a sustained way, and we suggest that such warming could cue beetles to emerge from their underground burrows and begin foraging. Although we acknowledge that this evidence is somewhat circumstantial, we hope that it offers useful insight to inspire further work about what triggers of foraging behavior in this very interesting beetle.

\section{Acknowledgements}

The authors thank Drs. David Langor and Jan Volney for their part in establishing the EMEND project and providing mentorship to JJ, CB and TW during work at EMEND. We also thank Evan Esch, for extremely capable work as a lab/field assistant and for discovering the $C$. frigidum burrow in the pickle jar. We also thank Canadian Forest Products (CANFOR) and Daishowa-Marubeni International Ltd. (DMI) for financial support of the project through the forest improvement association of Alberta (FRIAA), as EMEND provides a base for many interesting discoveries not in the mainstream of the experiment. Finally, we offer very special thanks to Ross and Joyce Bell whose enthusiasm for carabidology has inspired the three academic generations represented here to pursue carabidology and entomology from an enthusiastic biological perspective.

\section{References}

Burgess AF, Collins CW (1917) The genus Calosoma: Including studies of seasonal histories, habits, and economic importance of American species north of Mexico and of several introduced species. USDA Bureau of Entomology Bulletin 417: 1-124.

Cameron EA, Reeves RM (1990) Carabidae (Coleoptera) associated with gypsy moth, Lymantria dispar (L.) (Lepidoptera: Lymantriidae), populations subjected to Bacillus thuringiensis Berliner treatments in Pennsylvania. Canadian Entomologist 122: 123-129. doi: 10.4039/ Ent122123-1

Cobb TP, Langor DW, Spence JR (2007) Biodiversity and multiple disturbances: boreal forest ground beetle (Coleoptera: Carabidae) responses to wildfire, harvesting, and herbicide. Canadian Journal of Forest Research 37: 1310-1323. doi: 10.1139/X06-310 
Crins WJ (1980) Two aggregations of Calosoma frigidum (Coleoptera:Carabidae) in Ontario during 1976. Entomological News 91: 155-158.

Erwin TL (2007) A Treatise on the Western Hemisphere Caraboidea (Coleoptera): Their classification, distributions, and ways of life. Volume I (Trachypachidae, Carabidae Nebriiformes 1). Pensoft Publishers, Sofia-Moscow, 323 pp.

Felipe de Mendiburu (2009) agricolae: Statistical Procedures for Agricultural Research. R package version 1.0-7. http://tarwi.lamolina.edu.pe/ fmendiburu.

Jacobs J, Work TT, Spence JR (2008) Influences of succession and harvest intensity on ground beetle (Coleoptera: Carabidae) populations in the boreal mixedwood forests of Alberta, Canada: species matter. In: Penev L, Erwin T, Assmann T (Eds) Back to the Roots or Back to the Future? Towards a New Synthesis between Taxonomic, Ecological and Biogeographical Approaches in Carabidology, Proceedings of the XIII European Carabidologists Meeting, Blagoevgrad, Bulgaria, August 20-24 2007. Pensoft Publishers, Sofia, Bulgaria.

Jeffords MR, Case LJ (1987) Effect of prey density on diurnal activity and ovarian development in Calosoma calidum (Coleoptera: Carabidae): implications for biological control of the gypsy moth, Lymantria dispar (Lepidoptera:Lymantriidae) in the Mid-west. Great Lakes Entomologist 20: 93-97.

Koivula M, Spence JR (2006) Effects of post-fire salvage logging on boreal mixed-wood ground beetle assemblages (Coleoptera, Carabidae). Forest Ecology and Management 236: 102 112. doi: 10.1016/j.foreco.2006.09.004

Larochelle A, Larivière M-C (2003) A Natural History of the Ground-Beetles (Coleoptera: Carabidae) of America north of Mexico. Pensoft Publishers, Moscow-Sofia, 583 pp.

Lindroth CH (1961) The ground beetles of Canada and Alaska: Part 2. Opuscula entomologica, supplementa 20.

Loesh A (1977) Population of Calosoma frigidum (Coleoptera:Carabidae) in two areas of beech maple woods during an outbreak of Heterocampa guttivita (Lepidoptera:Notodontidae) on Beaver Iland Michigan. Great Lakes Entomologist 10: 166.

Parry D, Spence J, Volney W (1997) Responses of natural enemies to experimentally increased populations of the forest tent caterpillar, Malacosoma disstria. Ecological Entomology 22: 97-108. doi: 10.1046/j.1365-2311.1997.00022.x

R Development Core Team (2010) R: A language and environment for statistical computing. R Foundation for Statistical Computing, Vienna, Austria. ISBN 3-900051-07-0, URL http://www.R-project.org/

Sanders CJ, Frankenhuyzen KV (1979) High populations of a carabid beetle associated with spruce budworm. Environment Canada. Forestry Science. Bi-mon. Res. Notes. 35: 21-22. Spence JR, Niemelä JK (1994) Sampling Carabid Assemblages with Pitfall Traps - the Madness and the Method. Canadian Entomologist 126: 881-894. doi: 10.4039/Ent126881-3

Spieles DJ, Horn DJ (1998) The Importance of Prey for Fecundity and Behavior in the Gypsy Moth (Lepidoptera: Lymantriidae) Predator Calosoma sycophanta (Coleoptera: Carabidae). Environmental Entomology 27: 458-462.

Vasik K (1972) A biological method of control of Lymantria dispar L. and Diprion pini L. A. Calosoma sycophanta. Institute of Forestry and Wood Industry, Belgrade, Yugoslavia. 
Wagner TL, Leonard DE (1980) Mortality factors of satin moth,Leucoma salicis [Lep.: Lymantriidae], in aspen forests in Maine. BioControl 25: 1573-8248.

Weseloh RM (1985) Changes in Population Size, Dispersal Behavior, and Reproduction of Calosoma sycophanta (Coleoptera: Carabidae), Associated with Changes in Gypsy Moth, Lymantria dispar (Lepidoptera: Lymantriidae), Abundance. Environmental Entomology 4: 370-377.

Weseloh RM (1993) Adult feeding affects fecundity of the predator, Calosoma sycophanta (Col.: Carabidae). Entomophaga 38: 435-439. doi: 10.1007/BF02373075

Work TT, Jacobs JM, Spence JR, Volney WJ (2010) Increased green-tree retention required to maintain ground beetle biodiversity in boreal mixedwood forests Ecological Applications 20: 741-751. doi: 10.1890/08-1463.1

Work TT, Shorthouse DP, Spence JR, Volney WJA, Langor D (2004) Stand composition and structure of the boreal mixedwood and epigaeic arthropods of the Ecosystem Management Emulating Natural Disturbance (EMEND) landbase in northwestern Alberta. Canadian Journal of Forest Research 34: 417-430. doi: 10.1139/x03-238 